\title{
Health service providers in Somalia: their readiness to provide malaria case-management
}

\author{
Abdisalan M Noor*1,2, Ismail A Rage ${ }^{3}$, Bruno Moonen ${ }^{4}$ and \\ Robert W Snow ${ }^{1,2}$
}

\author{
Address: ${ }^{1}$ Malaria Public Health and Epidemiology Group, Centre for Geographic Medicine, KEMRI - Wellcome Trust Research Programme, \\ Nairobi, Kenya, ${ }^{2}$ Centre for Tropical Medicine, Nuffield Department of Clinical Medicine, University of Oxford, CCVTM, Oxford, UK, ${ }^{3}$ Centre for \\ International Health and Development Institute of Child Health, University College London, 30 Guilford Street, London WC1N 1EH, UK and \\ ${ }^{4}$ The Clinton Foundation, Timau Plaza, Argwings Kodhek Road, 2011, 00100, Nairobi, Kenya \\ Email: Abdisalan M Noor* - anoor@nairobi.kemri-wellcome.org; Ismail A Rage - i.kassim@ich.ucl.ac.uk; \\ Bruno Moonen - bmoonen@clintonfoundation.org; Robert W Snow - rsnow@nairobi.kemri-wellcome.org \\ * Corresponding author
}

Published: 13 May 2009

Malaria Journal 2009, 8:100 doi:10.1186/1475-2875-8-100
Received: 14 February 2009

Accepted: 13 May 2009

This article is available from: http://www.malariajournal.com/content/8/I/100

(C) 2009 Noor et al; licensee BioMed Central Ltd.

This is an Open Access article distributed under the terms of the Creative Commons Attribution License (http://creativecommons.org/licenses/by/2.0), which permits unrestricted use, distribution, and reproduction in any medium, provided the original work is properly cited.

\begin{abstract}
Background: Studies have highlighted the inadequacies of the public health sector in sub-Saharan African countries in providing appropriate malaria case management. The readiness of the public health sector to provide malaria casemanagement in Somalia, a country where there has been no functioning central government for almost two decades, was investigated.
\end{abstract}

Methods: Three districts were purposively sampled in each of the two self-declared states of Puntland and Somaliland and the south-central region of Somalia, in April-November 2007. A survey and mapping of all public and private health service providers was undertaken. Information was recorded on services provided, types of anti-malarial drugs used and stock, numbers and qualifications of staff, sources of financial support and presence of malaria diagnostic services, new treatment guidelines and job aides for malaria case-management. All settlements were mapped and a semi-quantitative approach was used to estimate their population size. Distances from settlements to public health services were computed.

Results: There were 45 public health facilities, 227 public health professionals, and 194 private pharmacies for approximately 0.6 million people in the three districts. The median distance to public health facilities was $6 \mathrm{~km}$. $62.3 \%$ of public health facilities prescribed the nationally recommended anti-malarial drug and $37.7 \%$ prescribed chloroquine as first-line therapy. $66.7 \%$ of public facilities did not have in stock the recommended first-line malaria therapy. Diagnosis of malaria using rapid diagnostic tests (RDT) or microscopy was performed routinely in over $90 \%$ of the recommended public facilities but only $50 \%$ of these had RDT in stock at the time of survey. National treatment guidelines were available in $31.3 \%$ of public health facilities recommended by the national strategy. Only $8.8 \%$ of the private pharmacies prescribed artesunate plus sulphadoxine/pyrimethamine, while $53.1 \%$ prescribed chloroquine as first-line therapy. $31.4 \%$ of private pharmacies also provided malaria diagnosis using RDT or microscopy.

Conclusion: Geographic access to public health sector is relatively low and there were major shortages of appropriate guidelines, anti-malarials and diagnostic tests required for appropriate malaria case management. Efforts to strengthen the readiness of the health sector in Somalia to provide malaria case management should improve availability of drugs and diagnostic kits; provide appropriate information and training; and engage and regulate the private sector to scale up malaria control. 


\section{Background}

The adoption into policy since 2004 of new artemisininbased combination treatments (ACT) for uncomplicated malaria has been almost universal across Africa [1]. However, there have been delays in the deployment of these new, efficacious medicines due to concerns about sustained financing, difficulties in integrating revised recommendations into national standard treatment guidelines and drug procurement and distribution to the periphery of the health sector [2-8]. Several studies have highlighted inadequacies of the formal public health sector to guarantee appropriate levels of drugs, training and guidelines to all their service providers several years after the introduction of new ACT drugs [7,9-11]. These studies serve as a reminder that having recommendations for efficacious drugs does not necessarily translate into a health system prepared to deliver these new medicines to target patients.

Somalia revised its national malaria treatment policy in May 2005, abandoning chloroquine as first-line treatment for uncomplicated malaria in favour of a combination of co-administered artesunate and sulphadoxine-pyrimethamine (AS-SP) [12], which was shown to have an adequate clinical and parasitological response by day 28 of between $95 \%$ and $99 \%$ across three sites in the country [13]. Quinine was recommended as second-line therapy for treatment failures at both hospitals and Mother and Child Health (MCH) facilities [12]. Diagnosis of malaria was to be undertaken using rapid diagnostic tests (RDT) or microscopy at all health facilities except the lower level health posts where the use of clinical diagnosis and presumptive treatment with SP as first-line therapy was recommended. In case of treatment failure with SP at health posts, patients are to be referred to higher-level facilities for treatment [12].

Civil war has ravaged Somalia for over 19 years causing untold suffering, famine and displacement of its population. In 2000, efforts were made by the international community to support the fragile health system and work toward a reconstruction of this sector to support the health needs of Somali's [14]. This coordinated effort received support from multiple international non-government organizations, bi-lateral agencies and support from the Global Fund for AIDS, TB and Malaria (GFATM) [15]. The Somali Aid Coordinating Body, comprised of development partners, UNICEF, WHO and the three ministries of health representing the three regions of Somalia, applied for support from the GFATM during round 2 and were awarded 12.9 million USD in 2002 to implement a new national malaria strategy [15], including the delivery of AS-SP as first-line treatment.

Very little is known about the current capacities of the public and private sector health services in Somalia and we present here the results of a rapid assessment of the extent, coverage and readiness of services able to provide malaria case-management in three districts.

\section{Methods}

\section{Study sites}

Three study districts were purposively sampled in consultation with the respective ministries of health and guided by the security clearance provided by the United Nations from each of the two self-declared republics in Somalia, (Somaliland, Puntland) and the region of south-central Somalia. The districts included Gebiley district, $50 \mathrm{~km}$ west of Hargeisa, the capital of Somaliland; Garowe/ Burtinle districts in Puntland; and Merka in south central Somalia, bordering the Indian Ocean and $100 \mathrm{~km}$ south of Mogadishu (Figure 1). The malaria ecologies vary between these three sites ranging from exceptionally arid and low population density areas in Garowe/Burtinle with low malaria transmission, Gebiley district with similar arid, low malaria transmission conditions but higher

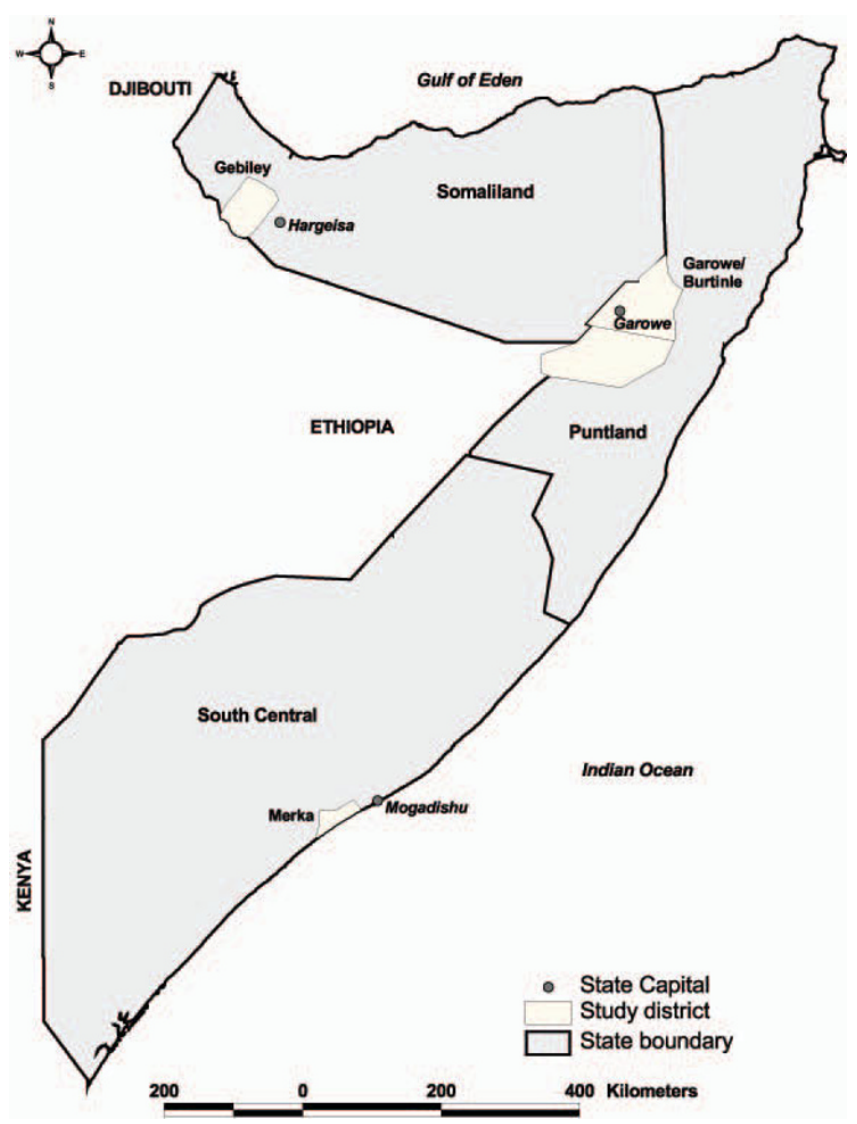

Figure I

Map of Somalia showing the two self-declared states (Puntland and Somaliland) and the south-central region; their capital cities; and the study districts. District boundaries are as defined by the local authorities and may not match internationally recognized boundaries. 
human population densities and Merka district with higher malaria transmission located closer to the Shabelle river, more intense agriculture and highest population density [16].

\section{Health facility and settlement mapping}

A baseline digital database of boundaries, settlements, roads and health facilities obtained from the Somalia office of the United Nations Development Programme (UNDP) was used to prepare initial district maps. In collaboration with local health authorities and elders these district maps were further modified to represent recent changes in the boundaries of health service provision for the district. Consultation with district-level health managers provided additional information on known health service providers. Field workers were selected by the respective state ministry of health in collaboration with the WHO local offices and were trained in the administration of survey questionnaires and use of a global positioning system (GPS: Garmin Etrex). Field workers were instructed to use the preliminary maps to confirm settlement locations and provisional population sizes and position all health providers managed by NGO's, ministries of health and private sector pharmacies and clinics and record a longitude and latitude for each structure or central position of each settlement. Provisional population totals were obtained from the UNDP settlement data and these were verified using household counts and discussions with village and clan elders. All assembled positional data were later overlaid on Google Earth imagery downloaded from [17] and captured between 2005 and 2007 to triangulate GPS positions.

Each survey team comprised of two interviewers, a driver and a locally appointed guide. In each district a total of five teams were involved in the survey and teams were assigned areas of relatively equal population/area. The survey took place from the $7^{\text {th }}-22^{\text {nd }}$ April 2007 in Gebiley; 25th October - 10 th $^{\text {th }}$ November 2007 in Garowe/ Burtinle; and 30th August - 9 9 $^{\text {th }}$ September 2007 in Merka.

\section{Facility audits}

Questionnaires were developed to record information on services provided, anti-malarial drugs in stock on the day of the survey, numbers and qualifications of staff, sources of financial support and presence and stock of malaria diagnostic services, new treatment guidelines and job aides for malaria case-management at public health facility. A less detailed questionnaire for private health facilities documenting the type of health facility; malaria services provided and type of drugs used for first- and second-line malaria treatment was also developed. Manuals were developed prior to the survey explaining the questionnaire and providing visual imagery of drugs and supporting case-management aides to assist in training and completion of the service provider audits. At each public and private health facility, the person in-charge at the time of visit was interviewed. Where a facility reported to have a microscope or rapid diagnostic tests (RDT) for malaria, these were confirmed by observation. The availability of trained laboratory technicians, however, was based on interviews of the person in charge of the health facility or pharmacy.

\section{Data entry and quality control}

At the end of the survey all the completed questionnaires were submitted to the local WHO-RBM offices. Each questionnaire was reviewed and inconsistencies were returned to survey teams to reconcile through follow-up visits. All health facility questionnaires data were entered in a customised screen with internal consistency checks developed using EpiData 3 (EpiData Association, Denmark). Spatial coordinates of health facilities and population settlements were imported into ArcGIS 9.1 (ESRI Inc., USA) and overlaid on pre-existing boundary and road maps and Euclidean distances from settlements, excluding the district capitals, to public health facilities were computed.

\section{Results \\ Distribution of service providers and population}

Table 1 shows the numbers of identified health service providers, population settlements and estimated population sizes. Population densities (per $\mathrm{Km}^{2}$ ), populationper-service provider and median distances from settlements outside the capitals of each district to the nearest service provider were computed (Table 1). The distribution of services and population are shown in Figures $2 \mathrm{a}-\mathrm{c}$ for each district. There were 21 public health service providers in Gebiley district; 10 in Garowe/Burtinle; 14 in Merka district. For each public health service provider there were, on average, 10,952 people in Gebiley; 7,300 in Garowe/Burtinle; 21,429 in Merka; representing an overall ratio of one public health facility for every 11,667 people. The median distances to public health services for settlements excluding the district capitals were highest in Garowe/Burtinle (24.2 km); followed by Gebiley (6.8 $\mathrm{km})$; and the shortest distances to public facilities were found in Merka $(4.6 \mathrm{~km})$ (Table 1$)$.

Of the 45 public health sector providers across the three districts, four were classified as hospitals providing inpatient care, 18 were second level out-patient providers of $\mathrm{MCH}$ services and general out-patient (OP) services, and 23 were classified as health posts that provide out-patient care services against a minimum set of essential drugs and staffed mainly by a single community health worker (Table 1). A total of 227 health personnel were stationed at the 45 health facilities and the majority were nurses $(30.8 \%, \mathrm{n}=70)$ or auxiliary nurses $(40.1 \%, \mathrm{n}=91)$. Only 11 qualified doctors were providing clinical services in the 
Table I: A description of population density and health service providers in three districts of Somalia in 2007

\begin{tabular}{|c|c|c|c|c|}
\hline & $\begin{array}{l}\text { Gebiley } \\
\text { district }\end{array}$ & Garowe/Burtinle districts & Merka district & Total \\
\hline Area within established district boundary $\left(\mathrm{Km}^{2}\right)$ & $4,228.1$ & $19,751.6$ & 1413.5 & $25,393.2$ \\
\hline Number of settlements indentified & 163 & 42 & 177 & 382 \\
\hline $\begin{array}{l}\text { Estimated total population (population density } \\
\text { per } \mathrm{Km}^{2} \text { ) }\end{array}$ & $\begin{array}{c}230,000 \\
(54.4)\end{array}$ & $\begin{array}{c}73,000 \\
(3.7)\end{array}$ & $\begin{array}{c}300,000 \\
(212.2)\end{array}$ & $\begin{array}{l}603,000 \\
(23.7)\end{array}$ \\
\hline Total number of public health facilities & 21 & 10 & 14 & 45 \\
\hline Hospitals & 1 & 1 & 2 & 4 \\
\hline MCH/OP facilities & 4 & 7 & 7 & 18 \\
\hline Health posts & 16 & 2 & 5 & 23 \\
\hline Population per public facility ratio & 10,952 per facility & 7,300 per facility & 21,429 per facility & II,667 per facility \\
\hline $\begin{array}{l}\text { Median }(\min , \max ) \text { distance from settlement to } \\
\text { public facility outside the district capital }(\mathrm{Km})\end{array}$ & $6.8(0.1,16.3)$ & $24.2(0.1,45.3)$ & $4.6(0.1,14.4)$ & $6.3(0.1,45.3)$ \\
\hline \multicolumn{5}{|l|}{ Staff per district } \\
\hline Doctors & I & 5 & 5 & 11 \\
\hline Nurses & 9 & 26 & 35 & 70 \\
\hline Auxillary Nurses & 15 & 32 & 44 & 91 \\
\hline Community Health Workers & 15 & 8 & 9 & 32 \\
\hline Laboratory technicians & 4 & 8 & 11 & 23 \\
\hline \multicolumn{5}{|l|}{ Total number of Private sector providers } \\
\hline Pharmacy alone & 32 & 36 & 79 & 147 \\
\hline Pharmacy + laboratory & 15 & 5 & 6 & 26 \\
\hline Pharmacy + clinic & 5 & 1 & 2 & 8 \\
\hline Pharmacy +laboratory+ clinic & 2 & 11 & 0 & 13 \\
\hline Population per pharmacy ratio & 4,260 per pharmacy & I,377 per pharmacy & 3,448 per pharmacy & 3,108 per pharmacy \\
\hline
\end{tabular}

$\mathrm{MCH} / \mathrm{OP}=$ Mother and Child Health/Out-patient facility

public health sector, at the time of the survey serving a total estimated population of 603,000 with only one doctor in Gebiley district. Only five facilities were directly supported by ministries of health, the remaining 40 were supported by NGOs, UNICEF, WHO and through partial cost-recovery. All public health facilities that had a microscope reported to have a trained laboratory technician.

The district mapping exercise identified 194 private health service providers, commonly referred as pharmacies, in the study districts: 54 in Gebiley district; 53 in Garowe/ Burtinle district; and 87 in Merka district. Of these, 147 $(75.8 \%)$ were pharmacies only, seven $(3.6 \%)$ were pharmacies with an attached clinic, $26(13.4 \%)$ were pharmacies with an attached laboratory but without a clinic, and $13(6.7 \%)$ were pharmacies with both clinic and laboratory (Table 1). Population-per-pharmacy ratios were considerably higher than public sector providers with one pharmacy for every 3,108 people. Considering the pharmacies with clinical services as providers of out-patient care, the private sector contributed approximately $31 \%$ of all out-patient care facilities across the three districts.

Provision of malaria treatment services in the public sector All public health facilities provided malaria treatment services but only 62.3\% (all hospitals and MCH/OPD and seven health posts) reported routinely prescribing the nationally recommended first-line anti-malarial treatment, and $37.8 \%$, of which $88 \%$ were in Gebiley district, reported the continued prescription of chloroquine as first-line treatment for malaria (Table 2, Additional File 1). Facilities reporting the adherence to the national firstline therapy were highest in Garowe/Burtinle districts ( $\mathrm{n}=$ $8,80.0 \%$ ) and lowest in Gebiley district where 15/21 $(71.4 \%)$ of health facilities reported providing chloroquine. Quinine, the second-line therapy for malaria, which is recommended to be used only at hospitals and MCH-OPD facilities, was prescribed in $91 \%$ of these facilities in the three districts (Table 2, Additional File 1). 

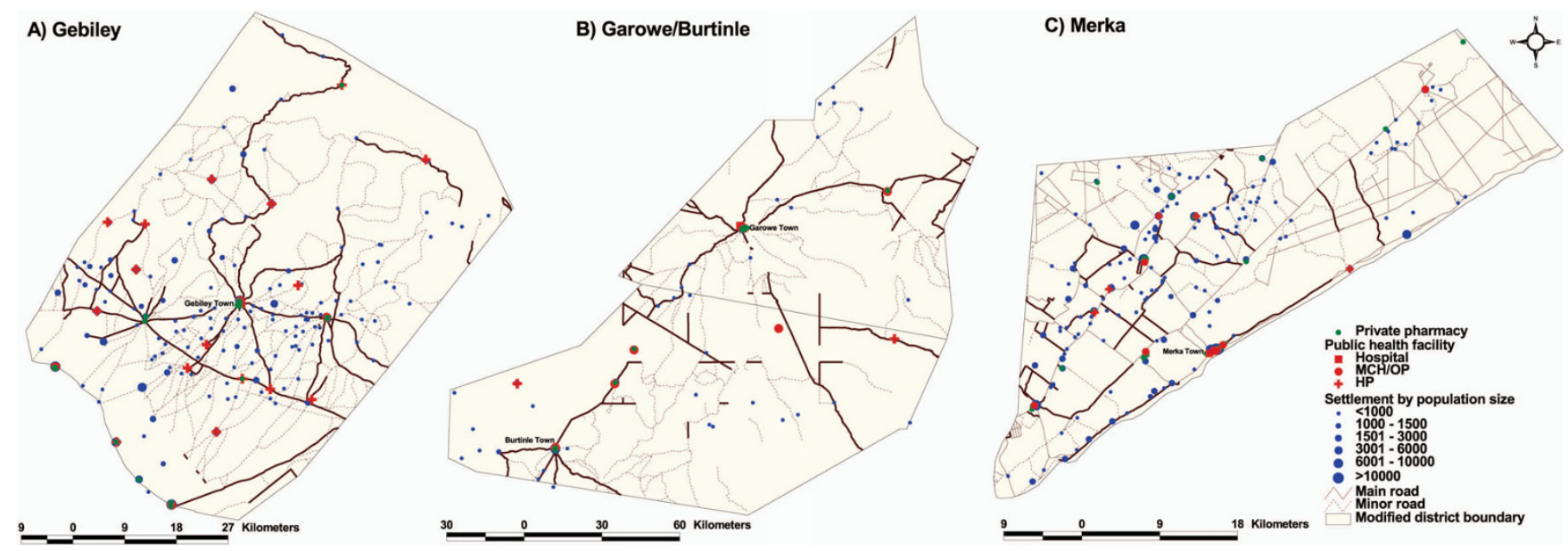

Figure 2

A-C Maps of study districts showing the location of public and private health facilities; and the distribution of settlements by population size. District boundaries are as defined by the local authorities and may not match internationally recognized boundaries.

Only $33.3 \%$ of public health facilities had the first-line anti-malarial drug of AS-SP or SP in stock on the day of the survey. Over $86 \%$ of hospitals and MCH/OP facilities had quinine in stock for treatment failures (Table 2). Revised national treatment guidelines, developed and distributed in 2006 using funds from GFATM were to be distributed only in the hospitals and $\mathrm{MCH} / \mathrm{OP}$ facilities but were available in $63.6 \%$ of these public health facilities (Table 2 ). Only $42.2 \%$ of facilities had job aides on the new national treatment guidelines in the form of wall charts (Table 2). Parasitological diagnosis, which was not recommended to be used in health posts, was routinely used in $91 \%$ of hospitals and $\mathrm{MCH} / \mathrm{OP}$ facilities with 54.5\% reporting the ability to perform microscopy in addition to the use of RDTs (Table 2). However, only 11/22 (50.0\%) of hospitals and MCH/OPD facilities had any RDT in stock at the time of survey. Thirty-seven percent of the public health facilities charged for malaria consultation, diagnosis or treatment; $53 \%$ of these facilities were in Gebiley district (Additional File 1).

\section{Private sector provision of malaria treatment}

Over $30 \%$ of pharmacies provided parasitological diagnostic services (Table 3). 3\% of pharmacies in Merka prescribed AS-SP, 9\% in Gebiley district and 18\% in Garowe/ Burtinle district. Between $8 \%$ and $37 \%$ of district-level pharmacists prescribed SP mono-therapy, with an average across the districts of $9 \%$ (Table 3 ). Up to $53 \%$ of private sector providers routinely prescribed chloroquine as the first-line anti-malarial therapy. Cotecxin ${ }^{\oplus}$, an artemisinin mono-therapy, was available in $22(42 \%)$ of pharmacies in Garowe/Burtinle district and $5(6 \%)$ of pharmacies in Merka district, none of the pharmacies in Gebiley district stocked Cotecxin ${ }^{\circledast}$.

\section{Discussion}

The availability of public health services was relatively low with only 45 public health facilities and 227 health professionals for approximately 0.6 million people and median distance to health facilities of $6 \mathrm{~km}$. This relatively poor access to health facilities is compounded by the generally bad public transport infrastructure in Somalia. All the health posts $(n=23)$ were manned by community health workers who had received minimal clinical training. Sixty-two percent of public health facilities prescribed the nationally recommended first-line therapy of AS-SP for hospital and MCH/OP and SP for health posts. Eightyeight percent of the health facilities that did not comply with the national first-line treatment guidelines were in Gebiley district of Somaliland. Importantly several public health facilities in 2007 were still prescribing chloroquine $(38 \%)$ as first-line therapy. $67 \%$ of public facilities that were compliant with the nationally recommended treatment guidelines did not have the first-line drugs in stock on the day of survey. Diagnosis of malaria using RDT or microscopy was performed routinely over $90 \%$ of the public health facilities but only half of these had RDT in stock at the time of survey. Malaria related information such as national treatment guidelines; and RDT wall charts were available respectively in between $60 \%$ and $80 \%$ of the hospitals and $\mathrm{MCH} / \mathrm{OP}$ facilities but dosing wall charts for AS-SP and SP monotherapy were available in only $42 \%$ of the target public health facilities. The private health sector, although four times larger than public sector in numbers of outlets, had only less than $10 \%$ prescribing AS-SP as the first-line therapy and the majority prescribed chloroquine (53\%) for this purpose. Interestingly over $30 \%$ of private pharmacies provided malaria diagnosis using RDT or microscopy. 
Table 2: Combined summaries of anti-malarial services provided by the public health service providers in the three study districts in Somalia

\begin{tabular}{|c|c|c|c|}
\hline & \multicolumn{3}{|c|}{ Total } \\
\hline & Hospital/MCH-OP $(n=22)$ & $H P(n=23)$ & All $(n=45)$ \\
\hline \multicolumn{4}{|l|}{ Reported use of anti-malarials for first-line treatment* } \\
\hline AS-SP & $21(95.5 \%)$ & 0 & $21(46.7 \%)$ \\
\hline SP & 0 & $7(30.4 \%)$ & $7(15.6 \%)$ \\
\hline Chloroquine & I (4.5\%) & $16(69.6 \%)$ & $17(37.8 \%)$ \\
\hline \multicolumn{4}{|l|}{ Reported use of anti-malarials for second-line treatment** } \\
\hline Never use & I (4.5\%) & $14(63.6 \%)$ & $15(33.3 \%$ \\
\hline Quinine & $20(91.0 \%)$ & $2(8.7 \%)$ & $22(48.9 \%)$ \\
\hline $\mathrm{SP}$ & I (4.5\%) & 7 (30.4\%) & $8(17.8 \%)$ \\
\hline Nationally recommended first-line therapy in stock on day of survey*** & $12(54.5 \%)$ & $3(13.0 \%)$ & $15(33.3 \%)$ \\
\hline Nationally recommended second-line therapy in stock on day of survey & $19(86.4 \%)$ & 0 & $19(42.2 \%)$ \\
\hline \multicolumn{4}{|l|}{ Parasitological diagnosis**** } \\
\hline None & $2(9.0 \%)$ & $23(100.0 \%)$ & $25(55.5 \%)$ \\
\hline RDT & $20(91.0 \%)$ & 0 & $20(44.4 \%)$ \\
\hline Microscopy & $12(54.5 \%)$ & 0 & $12(26.7 \%)$ \\
\hline RDT in stock on day of survey & II (50.0\%) & 0 & II (24.4\%) \\
\hline Revised national guidelines available at facility***** & $14(63.6 \%)$ & 0 & $14(31.1 \%)$ \\
\hline RDT use wall charts available at facility**** & $18(81.8 \%)$ & 0 & $18(40.0 \%)$ \\
\hline Anti-malarial dosing wall charts available at facility & $18(81.8 \%)$ & I (4.3\%) & $19(42.2 \%)$ \\
\hline Charging for malaria consultation, diagnosis or treatment & $8(36.4 \%)$ & $9(39.1 \%)$ & $17(37.7 \%)$ \\
\hline
\end{tabular}

$\mathrm{HP}=$ health post; $\mathrm{MCH} / \mathrm{OP}=$ Mother and Child Health/Out-patient facility; $\mathrm{SP}=$ sulphadoxine-pyrimethamine; $\mathrm{AS}-\mathrm{SP}=$ artesunate and SP; RDT = rapid diagnostic test

*National treatment guidelines recommend AS-SP as first-line therapy in hospitals and MCH/OP facilities and SP at health posts.

** National treatment guidelines recommend Quinine as second-line therapy in hospitals and MCH/OP facilities. The guidelines also recommend that health posts refer patients to MCH/OP or hospitals in case of treatment failure with AS-SP.

****First-line drugs were considered out of stock if a hospital or MCH/OP facility did not have either AS or SP or both and if a health post did not have SP on the day of survey.

****National treatment guidelines recommend the use of RDT or microscopy for diagnosis of malaria at hospitals and MCH/OP while at health posts clinical diagnosis and presumptive treatment are recommended.

Although this study represents the first of its kind in Somalia, there are a number of caveats to the results. First, the study was undertaken in only three purposively sampled districts and may not be nationally representative. The reason for adopting a purposive sample was due the logistical and security implications of undertaking such a study nationally in Somalia. The selected districts, however, represent the relatively more prosperous districts in the three study regions and the equivalent health sector indicators are probably only similar, if not poorer, for other districts. Second, information on training received by the private health sector workers was not recorded. This decision was made following advice by the local health authorities that owners of the many, probably unlicensed, private sector providers would interpret as 'police work' any questions on professional qualification and might have adverse security implications for field workers. Third, due to logistical and time constraints, a proper investigation of the performance of health workers in the public sector, in terms of appropriate diagnosis and treatment of malaria, was not undertaken. As a result, of those facilities that used the recommended anti-malarials, the proportion of health workers who prescribed the appropriate dosage was not recorded. Finally, these surveys and audits 
Table 3: Summary of anti-malarial services provided by the private health service providers in the three study districts in Somalia

\begin{tabular}{|c|c|c|c|c|}
\hline & $\begin{array}{c}\text { Gebiley } \\
\mathrm{n}=54\end{array}$ & $\begin{array}{c}\text { Garowe/Burtinle } \\
\qquad n=53\end{array}$ & $\begin{array}{l}\text { Merka } \\
n=87\end{array}$ & $\begin{array}{c}\text { Total } \\
n=194\end{array}$ \\
\hline Do not provide malaria diagnosis and treatment & $4(8 \%)$ & $0(0 \%)$ & $4(5 \%)$ & $8(4.1 \%)$ \\
\hline \multicolumn{5}{|c|}{ Pharmacy stocks and prescribes as first line treatment for malaria } \\
\hline AS-SP & $5(9 \%)$ & $9(18 \%)$ & $3(3 \%)$ & $17(8.8 \%)$ \\
\hline SP & $20(37 \%)$ & $4(8 \%)$ & $12(14 \%)$ & $18(9.3 \%)$ \\
\hline Chloroquine & $24(44 \%)$ & $18(34 \%)$ & $61(70 \%)$ & $103(53.1 \%)$ \\
\hline Quinine & I (2\%) & $0(0 \%)$ & $2(2 \%)$ & $3(1.5 \%)$ \\
\hline Cotecxin ${ }^{\circledR}$ & $0(0 \%)$ & $22(42 \%)$ & $5(6 \%)$ & $27(13.9 \%)$ \\
\hline \multicolumn{5}{|l|}{ Provide parasitological services* } \\
\hline RDT & $10(18.5 \%)$ & 7 (I3.2\%) & 7 (8.0\%) & $24(12.3 \%)$ \\
\hline Microscopy & 14 (25.9\%) & $16(30.2 \%)$ & 7 (8.0\%) & 37 (19.1\%) \\
\hline
\end{tabular}

$\mathrm{SP}=$ sulphadoxine-pyrimethamine; $\mathrm{AS}-\mathrm{SP}=$ artesunate and $\mathrm{SP} ; \mathrm{RDT}=$ rapid diagnostic test

*an additional 22 pharmacies which did not have an attached laboratory used rapid diagnostic tests for parasitological diagnosis of malaria

were only undertaken once in each district during 2007, as such the results represent only a single snap-shot description of the status of service provision in Somalia. However, these audits are useful exercises to guide areas of policy implementation and could serve, assuming a stabilizing of the security situation, as longitudinal sites to measure progress toward national malaria control effort.

The Somalia national malaria strategy has outlined a series of recommendations for malaria case management including the provision of prompt access to appropriate treatment; provision of relevant information to health workers for appropriate case management; the performance of malaria diagnosis using RDT or microscopy at hospitals and MCH/OPD health facilities; and engagement of the informal sector in the provision of these services [12]. On the basis of the acceptance of the new treatments guidelines two-thirds of the public health sector complied but any practical implementation of the policy was hampered by the widespread shortages in drugs and diagnostic tests. There is need to expand the health services to alleviate the long distances people are likely to walk to access health care given the poor state of public transport; establish efficient systems that can overcome the severe shortages of drugs and diagnostic materials; and improve adherence to recommended diagnosis and prescription through in-service training and job aides notably at the peripheral health posts which serve majority of the rural communities. The national malaria strategy should also be revisited to review the continued use of SP at health posts given that this drug has failed and is no longer in use in most African countries.
The service provider audit highlights the prolific nature of the private health sector in Somalia. This scales with recent findings from a national household sample survey of fevers and their treatment, which documented that over $40 \%$ of children who had fever in the two weeks prior to survey sought treatment from the private sector compared to only $8 \%$ from the public sector [18]. There is a growing recognition internationally of the role of the private sector in the treatment of malaria $[19,20]$. In Somalia the private sector is perhaps more sophisticated than many other settings in Africa, 30\% provided a combination of parasitological diagnosis and anti-malarial treatment. However, as with other settings [21] private sector providers continue to prescribe non-recommended malaria treatments. Ministries of health and stakeholders need to create mechanisms to engage, support and regulate the private sector in Somalia. Population distributions in Somaliland and Puntland converge around main roads and intersections where private health service providers are located for market reasons; the less well-served sparsely distributed and remote rural settlements populations require investments in public health sector provision, as these will still remain the main source of care for these communities.

\section{Competing interests}

The authors declare that they have no competing interests.

\section{Authors' contributions}

AMN was responsible for study design, data cleaning, analysis, interpretation and production of the final manuscript. 
IAR contributed to data collection, cleaning and analysis and production of final manuscript.

$\mathrm{BM}$ contributed to the design of the questionnaires and data entry platform and was involved in the production of final manuscript.

RWS was responsible for overall scientific management, analysis, interpretation and preparation of the final manuscript.

\section{Additional material}

\section{Additional file 1}

Summary of anti-malarial services provided by the public health service providers in the three study districts in Somalia.

Click here for file

[http://www.biomedcentral.com/content/supplementary/14752875-8-100-S1.rtf]

\section{Acknowledgements}

We thank the support provided by the respective ministries of health in South Central Somalia, Somaliland, notably Dr Hussein Hersi of Merlin, Dr Hussein Elmi of WHO and Dr Hussein Hirey of Comitato di Coordinamento delle Organizzazioni per il Servizio Voluntario (COSV) in Merka; Dr Waqar Butt, Mr Fahim Yusuf and Mr Farah Sahin of WHO-RBM and Dr Ahmed Noor of Gebiley District Hospital in Somaliland; Dr Sheikh Ali, Mr Faisal Warsame and Mr Abdi Hassan of WHO for their supervisory responsibilities in Puntland. We are also grateful to Dr Hoda Atta and Dr Zamani Ghasem of WHO-EMRO, Cairo and Tanya Shewchuk of UNICEF Somalia who enabled and guided the survey. The authors are grateful to Drs Dejan Zurovac and Pete Gething for their comments on earlier drafts of the manuscript and to Victor Alegana for his help with the production of the maps.

\section{Financial support}

Financial support was provided by GFATM (SOM-202-G0I-M-00) via WHO-EMRO (SOM/MAL/00I) to the Wellcome Trust, UK (\#079080). AMN is supported by the Wellcome Trust as a Research Training Fellow (\#081829). RWS is supported by the Wellcome Trust as Principal Research Fellow (\#079080). Both AMN and RWS acknowledge the support of the Kenyan Medical Research Institute.

\section{References}

I. Bosman A, Mendis KN: A major transition in malaria treatment: the adoption and deployment of artemisinin-based combination therapies. Am J Trop Med Hyg 2007, 77:193-197.

2. Williams HA, Durrheim DN, Shretta R: The process of changing national malaria treatment policy: lessons from countrylevel studies. Health Policy Plan 2004, 19:356-370.

3. Malik EM, Mohamed TA, Elmardi KA, Mowien RM, Elhassan AH, Elamin SB, Mannan AA, Ahmed ES: From chloroquine to artemisinin-based combination therapy: the Sudanese experience. Malar J 2006, 5:65.

4. Ogbonna A, Uneke C): Artemisinin-based combination therapy for uncomplicated malaria in sub-Saharan Africa: the efficacy, safety, resistance and policy implementation since Abuja 2000. Trans R Soc Trop Med Hyg 2008, 1 02:621-627.

5. Amin AA, Zurovac D, Kangwana BB, Otieno DN, Akhwale WS, Greenfield J, Snow RW: The challenges of changing national malaria drug policy to artemisinin-based combinations in Kenya. Malar J 2007, 6:72.

6. Sipilinyambe N, Simon JL, Chanda P, Olumese P, Snow RW, Hamer $\mathrm{DH}$ : From chloroquine to artemether-lumefantrine: The process of drug policy change in Zambia. Malar J 2008, 7:25.

7. Zurovac D, Tibenderana JK, Nankabirwa J, Ssekitooleko J, Njogu JN, Talisuna AO, Rwakimari JB, Meek S, Snow RW: Malaria case management under ACT treatment policy in Uganda. Malar J 2008, 7:181.

8. Kangwana BB, Njogu J, Wassuna B, Kadenge SV, Otieno DN, Goodman CA, Zurovac D, Snow RW: Malaria drug shortages in Kenya: A major failure to provide access to effective treatment. Am J Trop Med Hyg 2009, 80(5):737-8.

9. Zurovac D, Ndhlovu M, Sipilinyambe N, Chanda P, Hamer DH, Simon JL, Snow RW: Peadiatric malaria case-management with artemether-lumefantrine in Zambia: a repeat cross-sectional study. Malar J 2007, 6:31.

10. Zurovac D, Ngigi J, Akhwale WS, Hamer DH, Snow RW: Translation of artemether-lumefathrine treatment policy into paediatric clinical practice: an early experience from Kenya. Trop Med Int Health 2008, I 3:99-107.

II. Njogu J, Akhwale WS, Hamer DH, Zurovac D: Health facility and health worker readiness to deliver new national treatment policy for malaria in Kenya. East Afr Med J 2008, 85(5):213-22I.

12. Capobianco E: National Malaria Control Strategy 2005 - 2010 UNICEF; 2005.

13. Warsame M, Atta H, Klena John D, Butt AW, Elmi HH, Jibril AM, Hassan HM, Hassan AM: Efficacy of monotherapies, artesunatebased combination therapies in children with uncomplicated malaria in Somalia. Acta Trop 2008, 109: I46-I5I.

14. SACB: Strategic framework in support of the health sector in Somalia. Developed at the SACB health strategy development workshop, Nakuru; 2000.

15. GFATM Round 2 Somalia project proposal 2002 [http:// www.theglobalfund.org/search/docs/2SOMM 1340 full.pdf].

16. Noor AM, Clements ACA, Gething PW, Moloney G, Borle M, Shewshuk T, Hay SI, Snow RW: Spatial prediction of Plasmodium falciparum prevalence in Somalia. Malar J 2008, 7:I59.

17. Google Earth: [http://earth.google.com/]. Accessed I th January 2009

18. UNICEF, Multiple Cluster Indicator Surveys: [http://www.child info.org/mics.html]. Accessed: 25th January 2007

19. Goodman CA, Brieger W, Unwin A, Mills A, Meek S, Greer G: Medicine sellers and malaria treatment in sub-Saharan Africa: what do they do and how can their practice be improved? $\mathrm{Am}$ J Trop Med Hyg 2007, 77:203-218.

20. Buabeng KO, Duwiejua M, Matowe LK, Smith F, Enlund H: Availability and choice of antimalarials at medicine outlets in Ghana: the question of access to effective medicines for malaria control. Clin Pharmacol Ther 2008, 84:613-619.

21. Minzi OM, Haule AF: Poor knowledge on new malaria treatment guidelines among drug dispensers in private pharmacies in Tanzania: the need for involving the private sector in policy preparations and implementation. East Afr J Public Health 2008, 5(2): II7-12I.

\section{Publish with Bio Med Central and every scientist can read your work free of charge}

"BioMed Central will be the most significant development for disseminating the results of biomedical research in our lifetime. "

Sir Paul Nurse, Cancer Research UK

Your research papers will be:

- available free of charge to the entire biomedical community

- peer reviewed and published immediately upon acceptance

- cited in PubMed and archived on PubMed Central

- yours - you keep the copyright

Submit your manuscript here:

http://www.biomedcentral.com/info/publishing_adv.asp 